\title{
Determinants of Quality of Life Among Gynaecological Cancer Patients on Follow Up at a Referral Hospital in Kenya
}

\author{
Isaac Machuki Ogoncho ${ }^{1}$, Blasio Osogo Omuga ${ }^{2}$, Sabina Wakasiaka ${ }^{2}$, Margaret Muiva ${ }^{2}$ \\ ${ }^{1}$ Surgical Unit, Kisii Teaching and Referral Hospital, Kisii, Kenya \\ ${ }^{2}$ School of Nursing Sciences, University of Nairobi, Nairobi, Kenya
}

Email address:

isaacmachuki@gmail.com (I. M. Ogoncho), mitenga@yahoo.com (B. O. Omuga), swakasiaka@gmail.com (S. Wakasiaka), muiva@uonbi.ac.ke (M. Muiva)

\section{To cite this article:}

Isaac Machuki Ogoncho, Blasio Osogo Omuga, Sabina Wakasiaka, Margaret Muiva. Determinants of Quality of Life Among Gynaecological Cancer Patients on Follow Up at a Referral Hospital in Kenya. American Journal of Nursing Science. Vol. 4, No. 3, 2015 , pp. 127-130.

doi: 10.11648/j.ajns.20150403.22

\begin{abstract}
Various factors influence the quality of life (QOL) in cancer patients. This study sought to determine the predictors and factors associated with quality of life among gynaecological cancer patients on follow up at Kenyatta National Hospital, Kenya. A cross-sectional descriptive study was carried out between April and June 2014, involving both outpatient and inpatient gynaecological cancer patients receiving care at the palliative care unit. A structured questionnaire adopting the Missoula Vitas Quality of Life Index was used to collect information on socio-demographics, clinical characteristics and their perceptions about quality of life. The association between socio-demographic and clinical factors with QOL was analyzed using one way ANOVA and linear regression analysis to identify the predictors of QOL. A total of 108 study patients were interviewed. Their mean age was 48 years with a range of 18 to 72 years. Age, level of education, marital status, occupation and monthly income were the socio-demographic factors significantly associated with QOL scores, $(p<0.05)$. The patients' type of cancer, type of cancer treatment, duration of illness and palliative care services were the clinical characteristics significantly associated with QOL scores, $(\mathrm{p}<0.05)$. Age, level of education, occupation, average monthly income, type of cancer treatment, duration of illness and type of cancer were the independent predictors of QOL. Vulnerable patients were those who were less educated, peasant farmers or casual workers, had a long duration of illness and underwent combined therapy. Age, education, occupation, income, type of cancer, type of cancer treatment and duration of illness were the determinants of quality of life among gynaecological cancer patients in the study. Sufficient attention should be given to the more vulnerable gynaecological cancer patients in identifying and addressing their specific needs by the palliative care team.
\end{abstract}

Keywords: Determinants, Quality of Life, Gynaecological Cancers, Socio-demographic Factors, Clinical Factors

\section{Introduction}

Quality of life (QOL) is the subjective evaluation of life as a whole or the patients' appraisal and satisfaction with their current level of functioning compared with what they perceive to be possible or ideal [15]. Given the multidimensional nature of QOL, there are various factors that determine and predict QOL among cancer patients.

Studies have reported the potential influence of socio-demographic factors on QOL. Marital status, level of education and employment has been associated with QOL among breast and gynaecological cancer patients $[3,18]$. The age of cancer patients has been known to vary their perception of body image and physical attractiveness hence their QOL. The influence of age on the QOL among gynaecological cancer patients was reported in these studies $[8,10]$. Spiritual support by the medical team impacts the QOL of patients with advanced cancer when they neared death [4].

The type of cancer, duration of illness and the treatment cancer patients undergo affects their physical and psychosocial wellbeing. Ovarian and endometrial cancer patients had better QOL than patients with vulva and cervical cancers [10]. Chronic pain in the lower back and hips among cervical cancer survivors has been attributed to late effects of radiotherapy which impairs their physical functioning [21]. Combined chemotherapy and radiotherapy treatments have 
been associated with vaginal stenosis and fibrosis for patients with cervical cancer leading to a reduced sexual desire and sexual performance $[5,13]$. Most patients treated for pelvic cancers such as cervical and endometrial, experience a permanent change in bowel habits after radiotherapy [1, 13].

Determinants of QOL can therefore be accurately obtained through getting the patients' experience with cancer and its treatment effects. Few studies have examined the determinants of QOL among cancer patients in Kenya particularly in a hospital setting. This study will not only establish the determinants of QOL but also identify the vulnerable gynaecological cancer patients requiring special attention from the health care providers. The main objective of the study was to establish the predictors and factors associated with quality of life among gynaecological cancer patients on follow up at Kenyatta National Hospital.

\section{Materials and Methods}

A cross sectional descriptive study was conducted among gynaecological cancer patients receiving palliative care at Kenyatta National Hospital between the months of April and June 2014. Both outpatient and inpatient gynaecological cancer patients being followed up at the palliative care unit were included in the study.

A structured questionnaire that adopted the Missoula Vitas Quality of Life Index (MVQOLI) was used to collect information on socio-demographics, clinical characteristics and their perceptions about QOL. A MVQOLI is a 26 item quality of life questionnaire with five subscales and one global QOL item. The five subscales include interpersonal, symptom, function, transcendent and wellbeing which represents the social, physical, spiritual and psychological domains respectively. All the study patients provided written informed consent for participation after reading and obtaining a full explanation of the study information sheet. Kenyatta National Hospital Ethics committee approved the study.

Stata version 11 was used for data analysis. The association between socio-demographic and clinical characterisitics with QOL was analyzed using one way ANOVA and linear regression analysis to identify the predictors of QOL.

\section{Results}

A total of 108 patients were enrolled in the study. Of these patients, 26(24\%) had ovarian cancer, 60(56\%) cervical, $21(19 \%)$ endometrial and $1(1 \%)$ vulva cancers. The mean age for the participants was 48 years with a range between $18-72$ years. The ages between 35 and 44 years were predominant, $39(36 \%)$. The study participants had low levels of education with only $11(10 \%)$ of them having attained a tertiary level of education. The patients were predominantly peasant farmers, $47(43 \%)$ and majority $59(55 \%)$ of them were married. The study patients were mainly Christians, 107(99\%) with most $77(71 \%)$ of them earning less than 5,000 Kenya shillings per month, Table 1.

There was a significant association between age, level of education, marital status, occupation, religion, monthly income and the mean total QOL scores, $(p<0.05)$. Age of the patient was significantly associated with the symptom subscale score, $(\mathrm{p}<0.001)$. There was also a significant association between level of education, occupation and marital status with symptom, function and transcendent subscale scores, $(\mathrm{p}<0.05)$. Occupation had a significant association with the interpersonal subscale score, $(p=0.032)$. The monthly income and age of the patient was significantly associated with the transcendent and wellbeing subscale scores, $(\mathrm{p}<0.05)$, Table 1.

Table 1. Association between socio-demographic factors and QOL scores

\begin{tabular}{|c|c|c|c|c|c|c|c|}
\hline Variables & $\begin{array}{l}\text { Frequency } N \\
(\%)\end{array}$ & $\begin{array}{l}\text { Function } \\
\text { Mean (SD) }\end{array}$ & $\begin{array}{l}\text { Interpersonal } \\
\text { Mean (SD) }\end{array}$ & $\begin{array}{l}\text { Symptom } \\
\text { Mean (SD) }\end{array}$ & $\begin{array}{l}\text { Transcendent } \\
\text { Mean (SD) }\end{array}$ & $\begin{array}{l}\text { Wellbeing } \\
\text { Mean (SD) }\end{array}$ & $\begin{array}{l}\text { Total QOL } \\
\text { Mean (SD) } \\
\end{array}$ \\
\hline \multicolumn{8}{|l|}{ Age } \\
\hline $18-24$ years & $9(8)$ & $8.3(3)$ & $5(0.87)$ & $13(13)$ & $-2.5(7.8)$ & $0.17(2)$ & $17(1.2)$ \\
\hline $35-44$ years & $39(36)$ & $5.7(10)$ & $-2.4(11)$ & $6.3(14)$ & $3.9(9)$ & $-6.4(8.7)$ & $16(3.3)$ \\
\hline $45-54$ years & $19(18)$ & $2.7(12)$ & $9.4(8.5)$ & $6.5(11)$ & $0.74(14)$ & $-11(11)$ & $16(4.1)$ \\
\hline $55-64$ years & $22(20)$ & $5.7(12)$ & $5.5(11)$ & $7.3(10)$ & $8.8(12)$ & $-2.9(17)$ & $17(4.7)$ \\
\hline$>65$ years & $19(18)$ & $6.8(10)$ & $17(9.7)$ & $13(4.1)$ & $17(7.9)$ & $11(17)$ & $21(3.4)$ \\
\hline \multicolumn{8}{|l|}{ Level of Education } \\
\hline None & $22(20)$ & $2.7(13)$ & $4.7(9.8)$ & $6.1(9.1)$ & $3.3(7)$ & $-13(9.8)$ & $15(2.6)$ \\
\hline Primary- incomplete & $29(26)$ & $6.2(11)$ & $10(13)$ & $10(9.1)$ & $9.1(16)$ & $3(18)$ & $19(5.3)$ \\
\hline Primary- complete & $12(11)$ & $7.9(3)$ & $-1.5(11)$ & $16(8.1)$ & $2.3(2.4)$ & $-3.9(3.1)$ & $17(1.3)$ \\
\hline Secondary- incomplete & $30(28)$ & $4.5(11)$ & $2.5(12)$ & $2.5(14)$ & $5.8(11)$ & $-5.6(12)$ & $16(4.2)$ \\
\hline Secondary-complete & $4(4)$ & $7.5(3)$ & $-4.1(5.3)$ & $18(3)$ & $18(12)$ & $5.3(7.5)$ & $19(1.9)$ \\
\hline Tertiary & $11(10)$ & $9.7(3.5)$ & $12(8.5)$ & $12(11)$ & $5(14)$ & $6.8(7.3)$ & $19(3.4)$ \\
\hline \multicolumn{8}{|l|}{ Occupation } \\
\hline Housewife & $9(8)$ & $11(5.3)$ & $0.44(11)$ & $-4.2(12)$ & $6.1(14)$ & $-6.1(10)$ & $16(4.5)$ \\
\hline Peasant farmer & $47(43)$ & $2.8(12)$ & $6.9(11)$ & $3.1(11)$ & $4.8(13)$ & $-3.4(16)$ & $16(4.7)$ \\
\hline Casual worker & $6(6)$ & $-3.8(15)$ & $-3.5(9.3)$ & $15(1.1)$ & $2(2.2)$ & $-8.8(9.6)$ & $15(1.6)$ \\
\hline Self employed & $22(20)$ & $8.9(9.3)$ & $1.8(14)$ & $17(7.4)$ & $6.9(8.7)$ & $-6.5(12)$ & $18(3.6)$ \\
\hline Formal employment & $18(17)$ & $8.6(3.7)$ & $11(11)$ & $13(8.5)$ & $14(11)$ & $5.2(14)$ & $20(3.2)$ \\
\hline Others & $6(6)$ & $7.2(2.8)$ & $5.2(.75)$ & $17(10)$ & $-4.6(8.9)$ & $0.58(2.2)$ & $18(1.1)$ \\
\hline$P$ value ${ }^{*}$ & & 0.009 & 0.032 & $<0.001$ & 0.009 & 0.079 & 0.012 \\
\hline
\end{tabular}




\begin{tabular}{|c|c|c|c|c|c|c|c|}
\hline Variables & $\begin{array}{l}\text { Frequency N } \\
(\%)\end{array}$ & $\begin{array}{l}\text { Function } \\
\text { Mean (SD) }\end{array}$ & $\begin{array}{l}\text { Interpersonal } \\
\text { Mean (SD) }\end{array}$ & $\begin{array}{l}\text { Symptom } \\
\text { Mean (SD) }\end{array}$ & $\begin{array}{l}\text { Transcendent } \\
\text { Mean (SD) }\end{array}$ & $\begin{array}{l}\text { Wellbeing } \\
\text { Mean (SD) }\end{array}$ & $\begin{array}{l}\text { Total QOL } \\
\text { Mean (SD) } \\
\end{array}$ \\
\hline \multicolumn{8}{|l|}{ Marital Status } \\
\hline Single & 21(19) & $7.6(7.1)$ & $9(12)$ & $14(10)$ & $7.4(12)$ & $4.4(10)$ & $19(3.2)$ \\
\hline Married & $59(55)$ & $3.3(12)$ & $5.3(11)$ & $5.3(12)$ & $5.8(13)$ & $-5.7(15)$ & $16(4.3)$ \\
\hline Widowed & $16(15)$ & $7.8(8.7)$ & $8.7(9.7)$ & $4.6(10)$ & $7.3(12)$ & $-0.13(16)$ & $18(4.6)$ \\
\hline Separated & $12(11)$ & $10(4.2)$ & $-5.3(14)$ & $17(5.2)$ & $4.3(6.9)$ & $-5.4(10)$ & $17(3.3)$ \\
\hline P value $^{*}$ & & $<0.001$ & 0.08 & 0.003 & 0.025 & 0.865 & 0.046 \\
\hline Protestant & $78(72)$ & $5.3(11)$ & $4.9(12)$ & $7.9(13)$ & $6.3(11)$ & $-1.3(14)$ & $17(4.2)$ \\
\hline Catholic & $29(27)$ & $6.4(9.3)$ & $6.3(11)$ & $8.7(8.9)$ & $6(14)$ & $-6.4(15)$ & $17(4.2)$ \\
\hline Muslim & $1(1)$ & $2.5(0)$ & $10(0)$ & $16(0)$ & $2(0)$ & $-20(0)$ & $16(0)$ \\
\hline$P$ value ${ }^{*}$ & & 0.755 & 0.864 & 0.808 & 0.111 & 0.933 & 0.931 \\
\hline \multicolumn{8}{|l|}{ Monthly Income } \\
\hline Less than 5,000 & $77(72)$ & $5.9(9.3)$ & $3.9(12)$ & $7(13)$ & $5(12)$ & $-2.5(13)$ & $17(4.2)$ \\
\hline $5,000-9,999$ & $22(20)$ & $2.9(15)$ & $8(11)$ & $11(8.7)$ & $3.9(7.8)$ & $-11(12)$ & $16(3.5)$ \\
\hline P value ${ }^{*}$ & & 0.221 & 0.237 & 0.114 & $<0.001$ & $<0.001$ & 0.002 \\
\hline
\end{tabular}

*ANOVA one-way analysis

The type of gynecological cancer, duration of illness, type of cancer treatment the patient was undergoing was significantly associated with mean total QOL scores, $(\mathrm{p}<0.05)$. There was a significant association between type of cancer and symptom, transcendent, interpersonal and wellbeing subscale scores, $(\mathrm{p}<0.05)$. The duration of illness and duration of palliative care was significantly associated with symptom and interpersonal subscale scores, $(p<0.05)$. The type of cancer treatment was significantly associated with all the five subscale scores, $(p<0.01)$. There was no significant association between the duration of time from the last cancer treatment with the mean total QOL scores, $(\mathrm{p}>0.05)$.

From the multivariate linear regression analysis, the patients' age, level of education, occupation, average monthly income, type of cancer treatment, duration of illness and type of cancer were the independent predictors of QOL. There was a negative influence on QOL among gynaecological cancer patients who were peasant farmers or casual workers, with a long duration of illness, on combination therapy and had primary level of education.

\section{Discussion}

Patients aged 65 years and above had higher physical, spiritual, psychological and total QOL scores compared to other age groups. This was consistent with findings of [8] but contrasted findings from a study by [10] who reported high physical and overall QOL scores among younger Turkish gynaecological cancer patients. The high QOL scores among this age group could be attributed to the positive coping mechanisms and social support older women in the African setting obtain from family and friends.

Occupation was significantly associated with QOL in the study. Gynaecological cancer patients who were formally employed had higher social, psychological, spiritual and total QOL scores compared to those who were peasant farmers and casual workers. Formal employment is associated with adequate social support based on the high income earnings. This finding has been supported by the works of [3].

Patients who earned more than 10,000 Kenyan shillings in this study had higher psychological and total QOL scores compared to those who earned less. This observation was consistent with other studies that have reported a significant association between monthly income and overall QOL [3, 9, 18]. High income earnings are associated with adequate social support while low income earnings are associated with poverty and low socioeconomic status in the society which are a risk to cancer development [12]. Cancer patients with lower socioeconomic status have a more limited access to health care and receive less aggressive treatment for their cancers hence poor QOL [6, 20]

Gynaecological cancer patients who had completed secondary and tertiary levels of education had higher total QOL scores compared to those with lower levels of education. Low levels of education have been associated with decreased awareness of the disease, late screening and presentation to health facilities with a resultant poor prognosis hence low QOL scores. These findings are consistent with those by [3] while lower levels of education have been associated with lower QOL scores in other similar studies $[16,17]$.

The study reported the lowest psychological and total QOL scores among the married patients. This contrasted findings from similar studies $[3,10,19]$ that reported higher overall QOL and role function scores among married cancer patients. The low psychological domain scores could be attributed to the body changes that made sexual relations among these patients and their partners difficult or uncomfortable as a consequence of cancer and its treatment effects.

Patients with ovarian and endometrial cancers had higher physical, social, psychological and total QOL scores compared to those with cervical and vulva cancers. This finding was supported by the work of [10]. This observation could be attributed to good prognosis following early diagnosis and the pathogenesis of ovarian and endometrial cancers. Patients with early stage ovarian cancer tended to have good prognosis following surgical treatment [2]. Endometrial cancer also has the best prognosis when diagnosed early and has a slow growth process and late metastasis [10]. However, lower total QOL scores among patients with ovarian cancer has been reported in another 
study [16].

A significant association was reported between the type of cancer treatment and total QOL scores, which was consistent with literature. Gynaecological cancer patients on surgical treatment had the highest total QOL scores, followed by those on chemotherapy with the least scores being reported among patients on radiotherapy. Other similar studies have supported this observation $[7,10]$. Radiotherapy treatment has been associated with a chronic and negative impact on QOL [1]. Accordingly, cancer patients treated with surgery or chemotherapy alone returned to relatively normal functioning as opposed to those treated with radiotherapy that were more likely to complain about urinary, sexual and gynaecological symptoms [11].

Based on the regression analysis, age, level of education, occupation, average monthly income, type of cancer treatment, duration of illness and type of cancer were reported to be the independent predictors of QOL among gynaecological cancer patients in this study. Similar studies have supported these findings $[8,16]$.

\section{Conclusion}

Age, education, occupation, income, type of cancer, type of cancer treatment and duration of illness were the determinants of quality of life among gynaecological cancer patients on follow up at the palliative care clinic in Kenyatta National Hospital. Age, level of education, occupation, average monthly income, type of cancer treatment, duration of illness and type of cancer were the predictors of QOL among these patients. Gynaecological cancer patients who were peasants or casual workers, had primary level of education, undergoing combination therapy and had a long duration of illness were vulnerable. Sufficient attention should be given to the vulnerable gynaecological cancer patients in identifying and addressing their specific needs by the palliative care team.

\section{References}

[1] Abayomi, J., Kirwan, J., Hackett, A., Bagnall, G. (2005). A study to investigate women's experiences of radiation enteritis following radiotherapy for cervical cancer. J Hum Nutr Diet 18: 353-363.

[2] Arriba, LN., Fader, AN., Frasure, HE., von Gruenigen, VE. (2010). A review of issues surrounding quality of life among women with ovarian cancer. Gynecol Oncol 119: 390-396.

[3] Awadalla, AW., Ohaeri, JU., Gholoum, A., \& et al. (2007). Factors associated with quality of life of outpatients with breast cancer and gynecologic cancers and their family caregivers: a controlled study. BMC Cancer 7: 102.

[4] Balboni, TA., Paulk, ME., Balboni, MJ., \& et al. (2010). Provision of spiritual care to patients with advanced cancer: associations with medical care and quality of life near death. J Clin Oncol 28(3): 445-452.

[5] Berclaz, G., Gerber, E., Beer, K., \& et al. (2002). Long term follow up of concurrent radiotherapy and chemotherapy for locally advanced cervical cancer: 12 year survival after radiochemotherapy. International Journal of Oncology, 20, 1313-1318.

[6] Bindman, AB., Grumbach, K., Osmond, D., \& et al. (1995). Preventable hospitalizations and access to health care. JAMA 274: 305-311.

[7] Chan, YM., Ngan, HY., Li, BY., \& et al. (2001). A longitudinal study on quality of life after gynecologic cancer treatment. Gynecol Oncol, 83(1): 10-19.

[8] Chan, KY., Chan, ML., Yau, TC., Li, CW., Cheng, HW., Sham, MK. (2012). Quality of life for Hong Kong Chinese patients with advanced gynaecological cancers in the palliative phase of care: a cross-sectional study. J Palliative Care 28(4): 259-266.

[9] Conde, DM., Pinto-Neto, AM., Cabello, C., \& et al. (2005). Quality of life in Brazilian breast cancer survivors age 45-65 years: associated factors. Breast J 11: 425-432.

[10] Goker, A., Guvenal, E., Yanıkkerem, E., Turhan, A., Koyuncu, FM. (2011). Quality of life in women with gynaecologic cancer in Turkey. Asian Pac J Cancer Prev 12: 3121-3128.

[11] Greimel, ER., Winter, R., Kapp, KS., \& Haas, J. (2009). Quality of life and sexual functioning after cervical cancer treatment: a long-term follow-up study. Psychooncology 18: 476-482.

[12] Kagawa-Singer, M. (1995). Socioeconomic and cultural influences on cancer care of women. Seminars in Oncology Nursing 11(2): 109-119.

[13] Klastersky, J., \& Lossignol, D. (2011). Supportive care for patients with gynaecological cancer. South Afr J Gynaecol Oncol 3(2): 54-57.

[14] Klee, MC., King, MT., Machin, D., \& Hansen, HH. (2000). A clinical model for quality of life assessment in cancer patients receiving chemotherapy. Ann Oncol 11: 23-30.

[15] Lehto, US., Ojanen, M., \& Kellokumpu-Lehtinen, P. (2005). Predictors of quality of life in newly diagnosed melanoma and breast cancer patients. Ann Oncol, 16, 805-16.

[16] Miller, BE., Pittman, B., Case, D., \& McQuellon, RP. (2002). Quality of life after treatment for gynaecologic malignancies: a pilot study in an outpatient clinic. Gynecol Oncol 87: 178-184.

[17] Peuckmann, V., Ekholm, O., Rasmussen, NK., \& et al. (2007). Health-related quality of life in long-term breast cancer survivors: Nationwide survey in Denmark. Breast Cancer Res Treat 104: 39-46.

[18] Redhwan, AA., Nagi, NMS., Ali, MMS., \& Almuasli, M. (2011). Quality of life among Breast cancer patient in Yemen. Asian Pacific J Cancer Prev 12: 2335-2341.

[19] Reis, N., Beji, NK., \& Coskun, A. (2010). Quality of life and sexual functioning in gynecological cancer patients: Result from quantitative and qualitative data. Eur J Oncol Nurs 14: 137-146.

[20] VanEenwyk, J., Campo, JS., \& Ossiander, EM. (2002). Socioeconomic and demographic disparities in treatment for carcinomas of the colon and rectum. Cancer 95: 39-46.

[21] Vistad, I., Cvancarova, M., Fossa, SD., \& Kristensen GB. (2011). A study of chronic pelvic pain after radiotherapy in survivors of locally advanced cervical cancer. J Cancer Surviv 5(2): 208-216. 